cattle, and as early as 1841 he gave arsenic to a mare infected with the disease.

When in the Tete district in 1856 the people were afflicted with a severe epidemic of smallpox, he tried to produce a vaccine by inoculating a heifer, but the inoculation failed to take; instead, he had to send to the Cape for a supply of vaccine. In the same year the Governor of Quelimane requested that he report on the causes of unhealthiness of Senna, a town on the Lower Zambesi. He attributed the ill-health to the low-lying nature of the land, polluted expanses of water, and decomposing vegetable matter.

Among other experiments, he carried out tests on the most suitable colours for clothing in the tropies; ho roported on a diseaso called 'maculo', now no longer' occurring in Africa, characterized by as spreading gangrene of the rectum; he described the earth-eating habits of natives in Northern Rhodesia; he wrote a vivid account of tropical ulcer among slaves; and he noticed that Africans living on a manioc diet, high in carbohydrates, suffered from disturbances of vision.

Livingstone was the first to record that the tick (Ornithodoros moubata) was the vector for relapsing fever; and he may have also been the first man of medicine to associate mosquitoes with malaria. He was aware of the great British expeditions to the Niger in 1832 and 1841 , both of which ended in disastor, and after studying the account by M'William of the second expedition he came to the con- clusion that quinine was effective against malaria if it was given at an early stage and in sufficient quantity. That led him to devise his pill, consisting of quinine and purgatives, which he was able to try out in a dramatic manner on two English hunters who were dangerously ill with fever at Lake Ngami, one companion of theirs having already died. At this time his wife and children also becarne infected with malaria; he troated them success. fully in the same kind of way. It was because of this treatment that he was able to travel right across Africa from west to east in $\mathbf{1 8 5 6}$, and maintain activities in the unhealthy areas of the Zambesi and Shire Rivers for more than four years.

Livingstone also deserves credit for some attempts which he failed to carry through. When near the East Coast, for example, he camo across trees in the forests of Senna which he thought were cinchonas, and he sent samples to England, only to learn from Kew that he had beon mistaken. At another time he tried to prepare chloroform for his wife when her baby was due; he had obtained some chloral hydrate, having read of Simpson's discovery, but lacked a suitable retort to prepare the anaosthetic. On at further oecasion he made use of electricity in treating a $\mathrm{Mr}$. Hamilton in Bechuanaland who was suffering from paralysis.

In all these endeavours and discoveries Livingstone was moved by a pure missionary spirit, never seeking to make use of his medical knowledge for pecuniary gain.

\title{
CHEMISTRY OF PLANT PIGMENTS
}

A SYMPOSIUM on the chemistry of plant pigments, organized by the Phytochemical Group, was held in the University of Aberdeen on September 23-24. Attention in recent year's has been given increasingly to pigments which are not readily analysed by conventional techniques either because of their lability or their intractability, and most of the substances discussed during the first day of the meeting fell into one or other of these two classes. Progress in the chemistry of the betacyanins and betaxanthins, for example, has been delayed because of their susceptibility to aerial oxidation during purification. In the first paper, Prof. M. Piattelli (Naples) described how he was able to separate these elusive nitrogenous colouring matters by fractionating plant extracts on polyamide columns. He found them occurring in plants of the Centrospermae as glycosides. Betanidin was the only aglycone of the many betacyanins, but he had discoverod as many as eight betaxanthin aglycones. These yellow pigments were found to be related in structure to betanidin and differ in that the leucodopachrome moicty of betanidin is replaced by proline, 4-hydroxyproline, glutamine, glutamic acid, aspartic acid, tyramine, dopamine, or methionine sulphoxide.

In the second lecture, Dr. F. G. Holliman (Leeds) summed up the results of several years work on the red phenazine pigments present in Pseudomonas aeruginosa. He presented convincing structural and synthetic evidence that they are 2-amino-10-methylphenazinium betaines. One of them, aeruginosin $B$, is unique as a natural product in having a sulphonic acid group on a heterocyclic system, and furthermore is only the second natural sulphonic acid to be diseovered, the first being the sulpholipid sugar moiety, sulphoquinivose. In the third paper, Prof. W. B. Whalley (London) also dealt with a Pseudomonas pigment, this time a blue pigment in $P$. lemmonieri. The compound, which analysed for CHON and the metal calcium, proved to be extremely intractable and did not respond to any of the usual physical methods of structure determination. After many attempts, Prof. Whalley eventually isolated a degradation product from chromium trioxide oxidation, a pyridone quinone with an $n$-octyl side-chain, but the full structure of the pigment remains to be elucidated.

'The afternoon session was devoted to the natural black pigmonts and began with an account of the melanins by Prof. R. A. Nicolaus (Naples). After discussing the chemical structure of sepiamelanin from cuttlefish ink, he went on to point out that whoroas all animal melanins examined (19 sources) were derived from 5,6-dihydroxyindole, plant molanins, such as that in Ustilago maydis spores and in nine other sources, wore derived from catechol. The question was raised, in discussion of this paper, whether plant melanins could justly be called melanins, since they did not contain nitrogen, and should instead be called humic acids. However, humic acids, as were described by Prof. R. D. Haworth (Sheffield) in the following paper, are organic pigments present in the soil, formed from decaying vegetation over the course of centuries. After a brief survey of the chemistry of humic acids, Prof. Haworth went on to outline his own recent investigations, which were based on the discovery that these compounds give electron spin resonance signals. He thought that humic acid consisted of an organic polycyclic 'core', which was responsible for electron spin resonance signals, to which metals, carbohydrates, phenolic and amino-acids are attached. He supported this view with the results from zine dust distillation of humic acids, which had produced xarnthone, anthraquinone and a series of alkylnaphthalenes. Tr. H. M. Hurst (Liverpool), in a paper on the phenolic. moieties in humic acid, described how he had obtained more than 30 phenolic compounds, all being lignin and flavonoid derived units, from mild reduction of humic acids with sodium amalgam in weak alkali. He suggester that humic acid was a polymer derived mainly from lignins and flavonoids, which, after microbial degradation, wero leached by rain-water from decaying leaves and deposited in the podzol. In the final paper on humic acids, Dr. R. I. Morrison (Macaulay Institute, Aberdeen) reported that, by oxidizing methylated humic acids with permanganato and identifying the products by gas chromatography, he had also obtained lignin-derived fragments. The products 
he identified included anisic, veratric, 3,4,5-trimethoxybenzoic, 4-methoxyisophthalic and isohemipinic acids.

The first paper presented on the second day was by Dr. J. C. Hughes (Norwich) and carried on the theme of humic acids, since it dealt with black and brown pigments formed in the potato after cooking or as a result of enzyme action. Production of the black pigment, an iron-chlorogenic acid complex, in cooked potatoes was greatly affected both by biochemical factors in the potato and by the environmental conditions in which the potato was grown; it could largely be prevented by adding citric acid to the cooking water. The level of browning, on the other hand, is determined principally by the amount of substrate (tyrosine) and not the amount of enzyme (phenolase) in the potato. Turning from vegetable to flower pigments, Prof. E. Bayer (Tübingen) then described his work on naturally occurring anthocyanin metal complexes. Protocyanin, the natural chelate in cornflowers, he showed, can be split to cyanin, polygalacturonic acid, iron and aluminium. He pointed out that the reason why eyanin, present in red roses, would not complex with metal to give a blue colour was because chelating metals in these petals are not freely available, as they are bound to other substances of higher complex stability.

Anthocyanin pigments occur widely in leaves as well as flowers of higher plants and are abundantly present, for example, in leaves of the Asiatic Coleus species from which the popular ornamental plants are derived. However, Prof. H. Eugster (Zurich), in examining the red pigments on loaves of East African Coleus spp., found, not anthocyanins, but some new types of quinonoid pigments. The structures of two, coloon $A$ and $B$ from Coleus ignarius (fam. Labiatae), proved relatively easy to determine; $A$ is a 2,5-hydroxynaphthaquinone with an isoprenoid attachment and $B$ is a related hydroquinone. Fuerstion, from Fuerstia africana (also Labiatae), proved to be unusually labile, being sensitive to acid bases and heat, but, by very skilful experimentation, Prof. Eugster had been able to show that it was a methylene-quinone, somewhat related. in structure to pristimerine.
Yellow xanthone pigments were the subject of the next paper by Dr. J. C. Roberts (Nottingham), who surveyed their occurrence in flowering plants (nine families), in fungi (three genera) and in lichens (one genus). He described methods of structural determination, and dealt specifically with tho identification of sterigmatocystin from Aspergillus versicolor and mangiferin from Mangifera indica. The latter xanthone has a $C$-glucosyl attachment and it thus formed a natural bridge to the next paper on naturally occurring $C$-glycosyl compounds by Prof. L. J. Haynes (Jamaica). He described the nuclear magnetic resonance evidence which supported $C$-glycosyl structures for mangiferin and related compounds, and outlined recent research on a new $C$-glucosylchromone in bitter aloes. The final paper by Dr. R. M. Horowitz (Pasadena) was on $C$-glycosylfavones, and in it he presented nuclear magnetic resonance evidence which proved that vitexin was 8- $C$-glucosylapigenin, isovitexin 6-C-glucosylapigenin and the lucenins 6,8-di- $C$-glucosyl-luteolins. $\mathrm{He}$ used similar data in very elegant fashion to show that the xylose in a $\mathrm{D}$-xylosylvitexin (isolated from oranges) was attached by a $\beta 1 \rightarrow 2$ link to the 8 -glucosyl residue, and that a $p$-hydroxybenzoic acid derivative of vitexin was similarly constituted.

The meeting ended with short reports on the xanthones in Kielmeyera spp. (M. T. Magalhaes, Brazil) and in Calophyllum spp. (F. Scheinmann, Salford), on the quinones in Tabebuia ipé (A. R. Burnett, Aberdeen), on a novel yellow fungus pigment from Paxillus involutus (R. L. Edwards, Bradford), on umbelliferone biosynthesis (D. J. Austin, Glasgow), and on the Aspergillus hydroxylating system (S. M. Bocks, Oxford). It was clear from this symposium that plant pigments continue to provide a challenge to the skill and ingenuity of the organic chemist and that problems remain which will take much effort to solve, unless dramatically new techniques become available. The attraction of their colour will always ensure abundant interest in the chemistry of these fascinating substances.

J. B. Harborne

\section{DESIGN METHOD}

\begin{abstract}
THE OXFORD DICTIONARY lists many different interpretations of the word 'design' used either as noun or verb, but it now has a new meaning in its own right: a subject to be studied for its own sake, regardless of any primary discipline involved. Design as a fundamental concept is on its way to becoming a science. In the sense of producing now and useful commodities of all kinds, it is seen as a major challenge to human ability. "The better understanding of the problems involved provides a task for the behavioural scientists. The better development of designers requires careful thought by management." The theoretical and practical values of pioneering inter-disciplinary thinking in the broad field of design had to be tested. That the task has proved more than successful is attested by the symposium sponsored by the Design and Innovation Group of the University of Aston in Birmingham (designate), convened in Birmingham during Soptember 2l-23, of which a copy of the preprints of the papers presented is now available*.

This volume undoubtedly brings together, in a substantial way and for the first time in Great Britain, the general trend of thought about tho nature and problems of design by many different people in many walks of life having wide experience in this field. Thirty papers dealing with design from inception to realization and utilization are included. Breadth of coverage is shown by the wide range of technologies and sciences represented; these are * Design Method Symposium, University of Aston in Birmingham Designate (Organized by the Design and Innovation Group.) Pp. 322. (Butterworths, London, 1965.)
\end{abstract}

architecture, behavioural sciences, chemical engineering, electrical engineering, electronics, ergonomics, fuel technology, information science, instrument technology, mechanical engineering, metallurgy, philosophy, physics, production engineering, psychology and sociology.

As if to emphasize the concept of the building and ultimate evolution of design science, the symposium is appropriately divided into six successive sections: (1) the design process; (2) human needs and satisfaction; (3) stages of design; (4) practical design and techniques; (5) realization; (6) design and management.

The design process is concerned with overviews of the total process of design. It is illustrated by five papers: "Design Methods Reviewed", by J. C. Jones; "Some American Views on the Design Process", by R. J. McCrory; "A Survey of Design Methodology", by W. E. Eder; "Proparatory Work for Research into Electronies Design", by H. V. Beck; and "Design Science", by S. A. Gregory. On the bases of experience in these fields, it is deduced that the time is ripe for research into design and the establishment of design science as an aid to the practical designer.

"All technological design attempts to fulfil some human need or provide somo satisfaction." The section on human. needs and satisfaction is concernod with establishing the concepts involved and exploring ways of finding out or measuring human needs. Herein, to guide constructive thinking, are a furthor fivo papers: "Design and Human Satisfaction", by W. H. Mayall ; "Invention, Design and Market Research", by A. F. Stobart; "Sociology and 